\title{
Investigation of the Surface Defects in N-Channel MOS Transistors Under Long-Term Low-Dose-Rate Irradiation
}

\author{
V. D. Popov ${ }^{1}$ \\ ${ }^{1}$ National Nuclear Research University, Moscow, Russia \\ Correspondence: V. D. Popov, National Nuclear Research University, Moscow, Russia. E-mail: \\ wdpopov@mail.ru
}

Received: October 25, 2016

Accepted: November 9, 2016

Online Published: March 21, 2017

doi:10.5539/jmsr.v6n2p16

URL: https://doi.org/10.5539/jmsr.v6n2p16

\section{Introduction}

Gamma-radiation is commonly used to study surface defects in MOS transistors. Early experiments show two stages of surface-defect formation in a MOS structure under low-intensity gamma irradiation (Popov \& Vin, 2014; Popov, 2016). On the first stage the defect formation take place on interface $\mathrm{Si}_{-} \mathrm{SiO}_{2}$ from the oxide side. This process is described by an exponential dependence (Rashkeev et al., 2002). In the second stage "additional" surface defects are formed from the $\mathrm{Si}$ side. Radiation defects of silicon migrated to interface $\mathrm{Si}_{-} \mathrm{SiO}_{2}$ from the semiconductor.

The goal of this paper is investigation of surface-defect formation in a MOS transistor using the changing of surface electron mobility.

\section{Description of Experiment}

MOS transistors with an $n$ channel in CMOS integrated circuits CD4069UBCN were used in the experimental study. The current-voltage characteristics of the transistors were measured with an Agilent Technologies B1500A Analyzer of semiconductor devices.

The samples were irradiated with gamma photons from a $\mathrm{Cs}^{137}$ source at dose rate of $1.0,0.1$ and $0.01 \mathrm{rad}(\mathrm{Si}) / \mathrm{s}$ in the passive mode (with all pins of the integrated circuit short circuited during irradiation). In experiment 3 microcircuits in which characteristics of 3 transistors were measured were used.

The density of surface defects was determined by a measuring of slope of transconductance $k$ of the transistors (Emel'anov, Zhukov, Loshkarev, \& Meshurov, 1995). Average arithmetic values were calculated. As parameters of structure MOS transistor ( $W$ and $L$ - width and length of the channel, and also gate capacitence per unit area $C_{o x}$ ) were unknown a relative changes of a slope of transconductance were analyzed

$$
\frac{k(0)}{k(D)}=\frac{\frac{\mu_{s}(0)}{2} \cdot \frac{W}{L} \cdot C_{o x}}{\frac{\mu_{S}(D)}{2} \cdot \frac{W}{L} \cdot C_{o x}}=\frac{\mu_{S}(0)}{\mu_{S}(D)}
$$

where $k(0)$ and $k(D)$ - values of a of slope of transconductance, and $\mu_{s}(0)$ and $\mu_{s}(D)$ - values of surface mobility of carriers before and after an dose $D$ irradiation, $W$ and $L$ - width and length of channel MOS transistor, $C_{o x}$ - gate capacitence per unit area.

From relative change of the slope of transconductance (1) resulted relative value of surface mobility $\mu_{s}(0) \mu_{\mathrm{s}}(0)$ in channel of MOS transistor was determined. In Sexton and Schwank (1985) the model in which change of surface mobility $\mu_{s}$ connected with surface defects density $N_{i t}$ is offered. This model looks like

$$
\mu_{S}(D)=\frac{\mu_{S(0)}}{1+\alpha\left(\Delta N_{i t}\right)^{\prime}},
$$

where $\alpha \approx 7 \cdot 10^{-13} \mathrm{~cm}^{2}$ - parameter of model, $\Delta N_{i t}$ - change of surface defect density.

\section{Experimental Results}

Results of definition of relative change of surface mobility of electron are presented in Figure 1. As it is possible to see, it was observed practically identical dose dependences of surface mobility for different dose rate radiation. Especially it is visible on an initial site on dependence $\left[\mu_{s}(D) / \mu_{s}(0)\right]$ from $D$. 


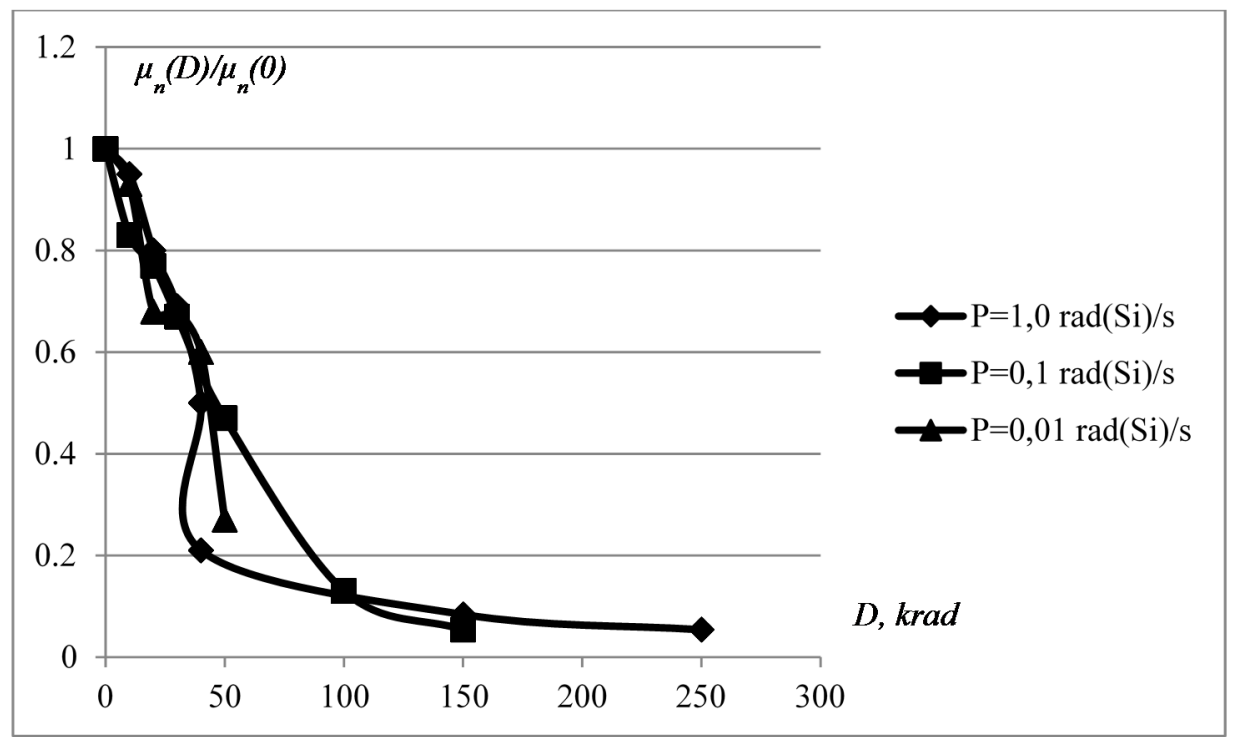

Figure 1. Change of relative surface mobility vs dose at dose rates 1.0, 0.1 and $0.01 \mathrm{rad}(\mathrm{Si}) / \mathrm{s}$

However, if to use the recommendation of work (Katerinich, Popov, \& Vin, 2012) in which it was offered to use time $t=D / P(P-$ dose rate $)$ instead of dose $D$ it is received obviously expressed two sites of change of surface mobility that (Figure 2) testifies to two stages of formation surface defects in MOS structure.

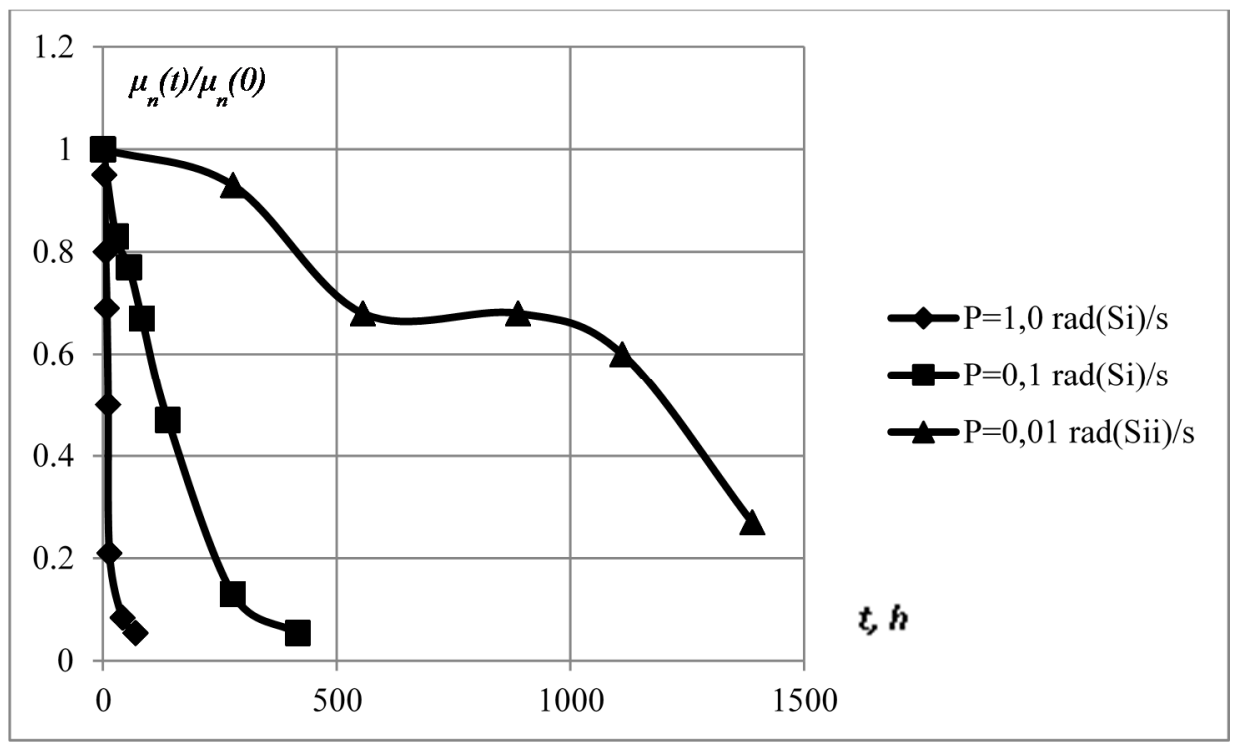

Figure 2. Change of relative surface mobility vs irradiation time at dose rates 1.0, 0.1 and $0.01 \mathrm{rad}(\mathrm{Si}) / \mathrm{s}$

The received results of experiment allowed to estimate change of surface defect density on interface $\mathrm{Si}_{-} \mathrm{SiO}_{2}$. Using model (2), dependences of surface defect density on time of an irradiation which are showen in Figure 3 have been obtained. For first stage the exponential dependence (Rashkeev et al., 2002).

$$
\Delta N_{i t}(t)=\Delta N_{i t . s}[1-\exp (-\beta t)]
$$

found and are listed in Table 1. In (3) it is $\Delta N_{\text {it.s }}$ - saturation of density of surface defects and $\beta$ - the parameter of model.

Subtracting from values of density of the surface defects received in experiment, the values designed with use (3), we receive density of "additional" surface defects $\Delta N_{i t}^{*}$. Change of these surface defects is shown on Figure 4 . As 
it is possible to see, there is some "threshold" value of time during which there is a migration of defects from silicon to interface $\mathrm{Si}_{-} \mathrm{SiO}_{2}$.

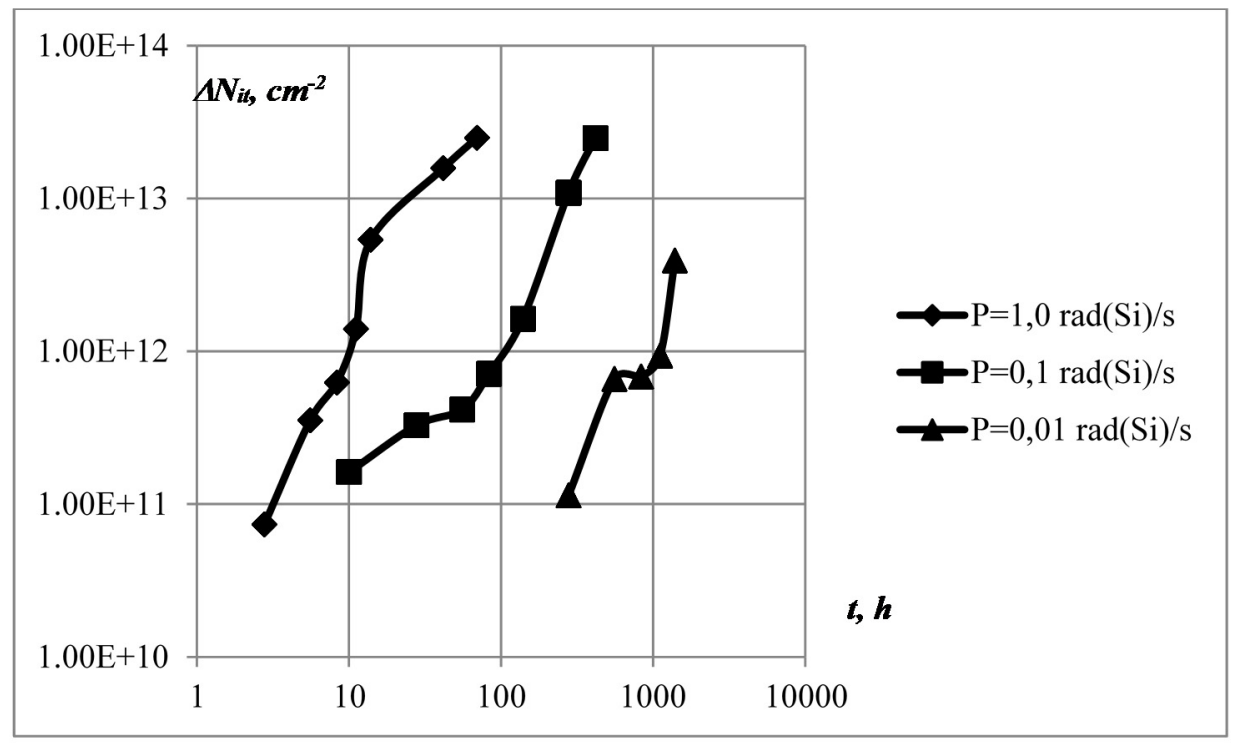

Figure 3. The change of density of surface defect vs irradiation time at dose rates 1.0, 0.1 and $0.01 \mathrm{rad}(\mathrm{Si}) / \mathrm{s}$

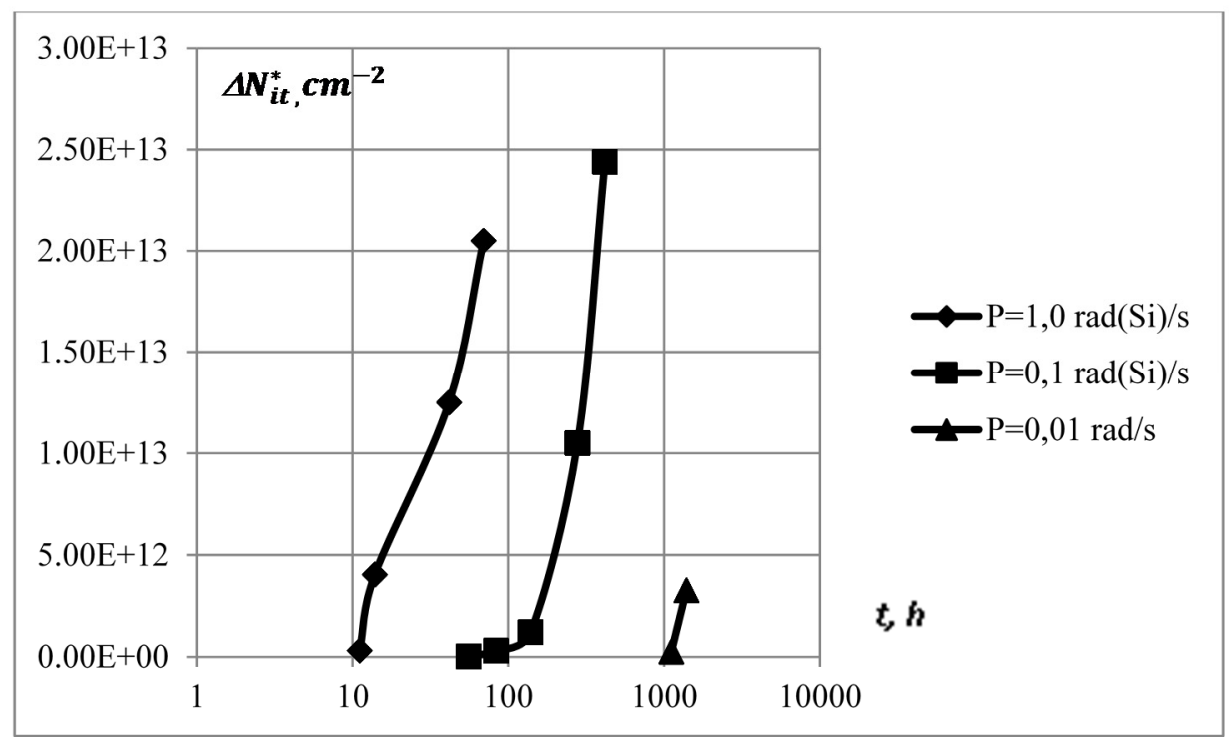

Figure 4. The defect migration for second stage vs irradiation time at dose rates 1.0, 0.1 and $0.01 \mathrm{rad}(\mathrm{Si}) / \mathrm{s}$

Table 1. Parameters of exponential dependence in the first stage

\begin{tabular}{ccc}
\hline$P, \operatorname{rad}(\mathrm{Si}) / \mathrm{s}$ & $\Delta N_{i t, s}, \mathrm{~cm}^{-2}$ & $\alpha, \mathrm{h}^{-1}$ \\
\hline 1.0 & $6,65 \cdot 10^{12}$ & 0,00162 \\
0.1 & $4,24 \cdot 10^{11}$ & 0,00482 \\
0.01 & $6,90 \cdot 10^{11}$ & 0,0062 \\
\hline
\end{tabular}

\section{Conclusion}

Low-intensity gamma irradiation MOS transistor at low ionizing-radiation dose rate $P$ allows to observe two stages surface-defect formation in structure $\mathrm{Si}_{-} \mathrm{SiO}_{2}$. At the first stage there is a formation of surface-defect formation at participation holes and the protons formed interface states from the side oxide. This process is well 
described by an exponential dependence, and the physical model of this process is stated, for example, in Rashkeev et al. (2002). At the second stage defects migrate on the part of silicon that increases their density $\Delta N_{i t}$ on interface $\mathrm{Si}-\mathrm{SiO}_{2}$ by side $\mathrm{Si}$. "Threshold" time of the beginning of the second stage is observed. The qualitative model of this process is described in (Popov, 2016).

Thus, both at Russian CMOS IC (Popov, 2016), and at the USA microcircuits, observed two stages surface-defect formation. At use dose dependences of surface-defect density $\Delta N_{i t}(D)$ these processes are difficultly distinct.

\section{Acknowledgments}

I am grateful to postgraduate student R.V.Vlasov for assistance in preparing data for the paper and to professor V.S.Pershenkov for useful discussion.

\section{References}

Emel'anov, V. V., Zhukov, Y. N., Loshkarev, V. V., \& Meshurov, O. M. (1995). Vopr. Atom. Nauki and Tech. Ser. Fizika Rad. Vozdeistv. on Radioelectron. Apparat, 3-4, 44.

Katerinich, I. I., Popov, V. D., \& Vin, C. K. (2012). Vopr. Atom. Nauki and Tech. Ser. Fizika Rad. Vozdeistv. on Radioelectron. Apparat, 1, 43.

Popov, V. D. (2016). Two Stages of Surface-Defect Formation in a MOS Structure under Low-Dose Rate Gamma Irradiation. Semiconductors, 50(3), 349-351.

Popov, V. D., \& Vin, C. K. (2014). Proceedings of the $13^{\text {th }}$ International Conference on Physics of Dielectrics. St/-Peterburg (Vol. 2, P. 234.). Russia. 2014.

Rashkeev, S. N., Cirba, C. R., Fleetwood, D. M., Schrimpf, R. D., Witczak, S. C., Michez, A., \& Pantelides, S. T. (2002). Physical model for enhanced interface-trap formation at low dose rates. IEEE Transactions on Nuclear Science, 49(6), 2650-2655.

Sexton, F. W., \& Schwank, J. R. (1985). Correlation of radiation effects in transistors and integrated circuits. IEEE Transactions on Nuclear Science, 32(6), 3975-3981.

\section{Copyrights}

Copyright for this article is retained by the author(s), with first publication rights granted to the journal.

This is an open-access article distributed under the terms and conditions of the Creative Commons Attribution license (http://creativecommons.org/licenses/by/4.0/). 